\title{
Establishment of a Rapid and Highly Sensitive Reverse-phase High-performance Liquid Chromatography Based Analytical Assay Method for Duvelisib
}

\author{
Dipali Sonawane, Amit Kumar Sahu, Tarang Jadav, Pinaki Sengupta* \\ National Institute of Pharmaceutical Education and Research-Ahmedabad (NIPER-A), An Institute of National Importance, \\ Government of India, Department of Pharmaceuticals, Ministry of Chemicals and Fertilizers, Gandhinagar, Gujarat, INDIA.
}

\begin{abstract}
Background: Duvelisib is an antineoplastic agent that received global approval from the United States Food and Drug Administration in 2018. An extensive literature search revealed that analytical method for the quantification of duvelisib at nanogram level is not available till date. A highly sensitive analytical method is necessary to analyze diversified samples containing trace levels of the analyte such as dissolution samples of sustained release formulation, cross-contamination study samples etc. Materials and Methods: Primary aim of this research was to develop a high throughput, accurate, reproducible, and highly sensitive high performance liquid chromatography method for quantification of duvelisib and validate according to the International Council for Harmonisation of Technical Requirements for Pharmaceuticals for Human Use and Association of Official Analytical Collaboration guidelines. Results: A linear relationship was confirmed over 70 to $5000 \mathrm{ng} / \mathrm{mL}$ concentrations with a limit of detection value of $20 \mathrm{ng} / \mathrm{mL}$. The intra and inter-day precision were found to be 0.97 to $1.87 \%$ and 1.25 to $1.99 \%$, respectively. Conclusion: This is the first time to report a quantitative assay method for duvelisib, which can quantify the analyte even at the nanogram level. This method will be suitable for sample analysis of quality control, stability, cross-contamination, dissolution study of sustained-release formulation and effluent analysis of duvelisib in pharmaceutical industries and research laboratories.
\end{abstract}

Key words: Duvelisib, HPLC, Analytical assay method, Development, Validation.

\section{INTRODUCTION}

Duvelisib (ABBV-954; COPIKTRA; INK1197; IPI-145; VS-0145) is a orally used drug having potential immunomodulating and antineoplastic activity. ${ }^{1}$ It falls under biopharmaceutical classification system (BCS) class IV category with less solubility and permeability. ${ }^{2}$ Pharmacologically, it inhibits phosphoinositide 3-kinases (PI3Ks) specifically $\delta$ and $\gamma$ isoforms (PI3K $\delta$ and PI3K $\gamma$ ), which helps malignant B-cells to grow and survive. ${ }^{3,4}$ PI3Ks are known for their crucial contribution towards maintaining cellular homeostasis. The significant involvement of the PI3K signalling is evidenced for modulation of various basic cellular functionalities of $\mathrm{B}$ and $\mathrm{T}$ cells. Compared to other classes, class I PI3Ks are found as $\alpha, \beta, \gamma$ and $\delta$ isoforms. ${ }^{5}$ Out of these, $\gamma$ and $\delta$ isoforms are only found in haematopoietic cells whereas, widespread expression of $\alpha$ and $\beta$ isoforms is found in normal cells. ${ }^{6,7}$ It is well known that PI3K- $\alpha$ has a significant role in tumor formation whereas, PI3K- $\beta$ is involved in thrombotic disorders. The remaining two isoforms (PI3K- $\gamma$ and $\delta$ ) have profound involvement in the process of inflammation and immune system regulation. ${ }^{8}$ Anomalies in the regulation of PI3K signaling pathway are responsible
Submission Date: 25-04-2021; Revision Date: 29-07-2021; Accepted Date: 25-11-2021.

DOI: 10.5530/ijper.56.1.34 Correspondence: Dr. Pinaki Sengupta National Institute of Pharmaceutical Education and Research (NIPER) - Ahmedabad, Opposite Air Force Station, Palaj, Gandhinagar-382355, Gujarat, INDIA.

E-mail: psg725@gmail.com

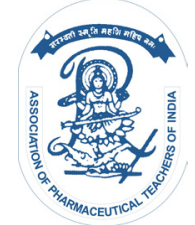

www.ijper.org 
for development of cancer in humans. PI3K enzyme inhibition has been proved to be an effective strategy in cancer treatment in recent years. Different PI3K inhibitors, namely idelalisib, duvelisib and copanlisib are commercially available in the treatment of cancer., Duvelisib is a newer class of molecule to treat hematological malignancies. ${ }^{2,10}$ It was marketed by Verastem Oncology as Copiktra for the oral treatment of cancers. ${ }^{11}$ Both $\delta$ and $\gamma$ isoforms of PI3K are inhibited by duvelisib. However, it exhibits high selectivity for PI3K- $\delta$, which is 10 -fold higher than that of PI3K- $\gamma{ }^{12}$ Duvelisib received global approval from the United States Food and Drug Administration (USFDA) in September2018. ${ }^{13}$ It is recommended against all types of lymphocytic leukaemia after two initial treatments. It received accelerated approval in the USA to treat follicular lymphoma after two initial treatments. It also got fast-track approval to treat follicular lymphoma owing to its overall response rate. ${ }^{12}$ It is recommended to administer duvelisib orally with $25 \mathrm{mg}$ dose two times a day. Chemically, duvelisib is ((S)-3-(1-(9H-purin6-ylamino)ethyl)-8-chloro-2-phenylisoquinolin-1(2H)one). Duvelisib is available in the market as $15 \mathrm{mg}$ and $25 \mathrm{mg}$ capsules. The major excipients present in the capsule are microcrystalline cellulose, colloidal silicon dioxide, crospovidone, and magnesium stearate. ${ }^{14}$

An extensive literature search confirmed unavailability of analytical techniques for quantitation of duvelisib atsub microgram level. The method reported by Srujani et al. for quantification of duvelisib can only quantify the analyte upto a lower limit of $6.25 \mu \mathrm{g} / \mathrm{mL}$ with a linear response. ${ }^{15}$ However, the method is not useful to analyze duvelisib at a low concentration. The method we have developed is about 90 times more sensitive than the previous method. Another method reported by Siddesh et al. is to simultaneously quantify copanlisib, duvelisib and idelalisib in rat plasma samples. ${ }^{16}$ The method can only be used to quantify the drugs in biological samples. Total run time of the method to quantify the analytes is $15 \mathrm{~min}$. However, the method we have reported here is much faster and the total run time (6 $\mathrm{min})$ is less than half of the method reported previously. Similarly, an ultra-performance liquid chromatography- tandem mass spectrometry (UPLC-MS/MS) method reported by Shao et al. is also not useful for quantification of duvelisib in analytical samples. The method is to quantitate duvelisib in beagle dog's plasma samples originated from pharmacokinetic studies. ${ }^{17}$ Therefore, there is an obvious need for establishment of a sensitive analytical method for duvelisib, which should be available in the public domain. The scope of this study was mainly inclined towards the development and validation of an analytical method, which can be useful to quantitate duvelisib as a drug substance or pharmaceutical dosage forms. ${ }^{18}$ Scientific community keeps on updating analytical methods to make them more simple, reliable, cost-effective, reproducible with a high level of accuracy and precision. ${ }^{19,20}$ Primary aim of this study was to develop and validate an accurate, precise, robust, rapid, selective, and highly sensitive high performance liquid chromatography (HPLC) method for quantification of duvelisib at very low concentration. Nanogram level detection is essential to analyze stability and cross-contamination samples in industry. The developed method achieved higher sensitivity against previously reported methods and was fully validated as per the guidelines recommended by the International Council for Harmonisation of Technical Requirements for Pharmaceuticals for Human Use (ICH), ${ }^{21}$ and the Association of Official Analytical Collaboration (AOAC). ${ }^{22}$

\section{MATERIALS AND METHODS}

\section{Chemicals and reagents}

Duvelisib (purity, 99.45\%) (Figure 1) was purchased from Renwik Bioinnovations, New Delhi (Batch No: CSN13707-002). HPLC grade acetonitrile (ACN) and methanol $(\mathrm{MeOH})$ were purchased from Thermo Fischer Scientific India Pvt Ltd. Ultra-purified water was collected from Millipore Milli-Q system (Synergy UV) in our laboratory and used throughout the study.

\section{HPLC instrumentation and chromatographic conditions}

The reversed phase (RP)-HPLC (Agilent 1260 Infinity series) system was assembled with a quaternary pump (DEADP18979), degasser, autosampler (DEADA00334), column oven, and a diode array detector (DEAAX08589). The system was operated by OpenLab software for

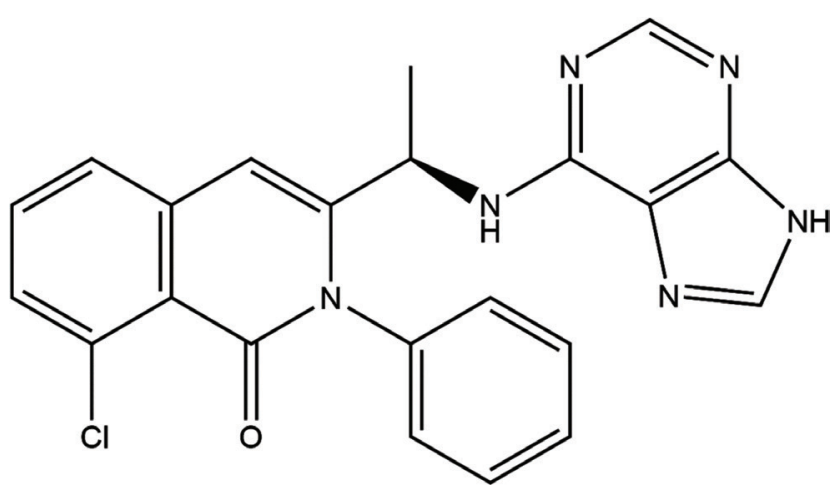

Figure 1: Molecular structure of duvelisib. 
controlling the instrument parameters. Separations were carried out on an $\mathrm{C}_{18}$ column $(250 \times 4.6 \mathrm{~mm}$, $5 \mu \mathrm{m}$ ) (Agilent Zorbax Eclipse Plus). The column was kept at $25^{\circ} \mathrm{C}$. A mobile phase mixture of $0.1 \%$ formic acid in water:ACN $(60: 40, \% \mathrm{v} / \mathrm{v})$ was used at a flow rate of $1 \mathrm{~mL} / \mathrm{min}$. The injection volume was $10 \mu \mathrm{L}$ and ultra violet (UV) detection was performed at $286 \mathrm{~nm}$ wavelength. The total run time was $6 \mathrm{~min}$. All standard solutions were prepared by weighing the analyte using a calibrated weighing balance (XS3DU, Mettler Toledo, Switzerland). Identification of duvelisib peak was ensured by comparing the retention time (RT) with standard injections.

\section{Preparation of standard and working solution}

Owing to the insolubility of duvelisib in water, ACN and $\mathrm{MeOH}$ were utilized as cosolvents. Different ratios of water and organic solvents were prepared and solubility was examined. Duvelisib was found to be less soluble in $\mathrm{ACN}$ and $\mathrm{ACN}$-water mixture. However, it was freely soluble in $\mathrm{MeOH}$-water mixture (50:50,\%v/v) and it was used as diluent. Finally, the standard solution of duvelisib was prepared in diluent in a $10 \mathrm{~mL}$ volumetric flask to obtain a $1000 \mu \mathrm{g} / \mathrm{mL}$ concentration. Working standard solution was generated after dilution of $1 \mathrm{~mL}$ of the above solution upto $10 \mathrm{~mL}$ to obtain $100 \mu \mathrm{g} / \mathrm{mL}$ concentration. The working solution was suitably diluted with diluent to get the final concentrations of $0.05,0.07,0.1,0.2,0.5,1,2$ and $5 \mu \mathrm{g} / \mathrm{mL}$.

\section{Method validation by RP-HPLC}

The developed RP- HPLC method was subjected to validtion for the different parameters such as limit of detection (LOD), limit of quantitation (LOQ), linearity, accuracy, precision (intra-day and inter day), robustness and specificity. ${ }^{23} \mathrm{ICH}$ Q2 R1 and AOAC guidelines were followed for setting the acceptance criteria of the validation study. ${ }^{24}$

\section{System suitability}

The chromatographic system should be checked for its suitability prior to the analysis to nullify the possibility of any variation caused by instrumental conditions. To ensure this, system suitability test was performed for the chromatographic system. The system suitability was evaluated by injecting six replicates of duvelisib $(1 \mu \mathrm{g} / \mathrm{mL})$. Various system suitability attributes like retention time, theoretical plate, asymmetry and tailing factor were evaluated.

\section{Sensitivity}

Sensitivity of the quantification method was established through the prediction of LOD and LOQ. LOD and
LOQ are the minimum concentration that can be detected and quantitated, respectively. As per the ICH guideline, LOD and LOQ can be determined by three methods, namely visual evaluation, signal to noise ratio and standard deviation of responses and slope. ${ }^{21}$ Here, we have used the standard deviation of responses and slope method to determine the LOD and LOQ.

The linearity levels were selected from 0.05 to $5.0 \mu \mathrm{g} / \mathrm{mL}$ for LOD and LOQ prediction. Seven different linearity concentrations including $0.05,0.1,0.2,0.5,1.0,2.0$ and $5.0 \mu \mathrm{g} / \mathrm{mL}$ were generated from the working standard solution $(100 \mu \mathrm{g} / \mathrm{mL})$ by serial dilution. A volume of $1 \mathrm{~mL}$ was diluted up to $10 \mathrm{~mL}$ with diluent $(\mathrm{MeOH}$ : water $(50: 50 \% \mathrm{v} / \mathrm{v}))$ mixture to achieve the concentration of $10 \mu \mathrm{g} / \mathrm{mL}$. Similarly, from $10 \mu \mathrm{g} / \mathrm{mL}$ solution, $5 \mathrm{~mL}$ and $2 \mathrm{~mL}$ were diluted up to $10 \mathrm{~mL}$ to have $5 \mu \mathrm{g} / \mathrm{mL}$ and $2 \mu \mathrm{g} / \mathrm{mL}$ levels, respectively. From $10 \mu \mathrm{g} / \mathrm{mL}$ solution, $1 \mathrm{~mL}$ was diluted up to $10 \mathrm{~mL}$ to get $1 \mu \mathrm{g} / \mathrm{mL}$ solution. Similarly, $0.05 \mu \mathrm{g} / \mathrm{mL}, 0.1 \mu \mathrm{g} / \mathrm{mL}, 0.2 \mu \mathrm{g} / \mathrm{mL}$ and $0.5 \mu \mathrm{g} / \mathrm{mL}$ samples were prepared from $1 \mu \mathrm{g} / \mathrm{mL}$ working standard solution. These solutions were analyzed by the HPLC system and peak areas were noted. From the peak area, standard error, slope, correlation coefficient and intercept were calculated. The LOD and LOQ were predicted from this calculated standard error and slope by using the following formula. ${ }^{25}$

$$
\begin{aligned}
& \text { LOD }=3.3 \times(\text { standard error of responses/slope }) \\
& \text { LOQ }=10 \times(\text { standard error of responses/slope })
\end{aligned}
$$

To confirm the predicted values, six replicates of $20 \mathrm{ng} / \mathrm{mL}$ and $70 \mathrm{ng} / \mathrm{mL}$ were injected individually as LOD and LOQ, respectively. From the peak area of the replicate injections, \% RSD was calculated.

\section{Linearity}

Linearity range was established by preparing seven different solutions of 0.07 to $5 \mu \mathrm{g} / \mathrm{mL}$ of duvelisib covering 7\% $(0.07 \mu \mathrm{g} / \mathrm{mL}), 10 \%(0.1 \mu \mathrm{g} / \mathrm{mL}), 20 \%$ $(0.2 \mu \mathrm{g} / \mathrm{mL}), 50 \%(0.5 \mu \mathrm{g} / \mathrm{mL}), 100 \%(1.0 \mu \mathrm{g} / \mathrm{mL})$, $200 \%(2.0 \mu \mathrm{g} / \mathrm{mL})$ and $500 \%(5.0 \mu \mathrm{g} / \mathrm{mL})$ of the target concentration. The graph was plotted between peak area on Y-axis versus their respective concentration $(\mu \mathrm{g} / \mathrm{mL})$ on the $\mathrm{X}$-axis. The regression equation was calculated from the plot.

\section{Accuracy}

Accuracy (closeness to true values) of the quantification method was determined from $\%$ recovery of duvelisib at three different levels of $80 \%, 100 \%$ and $120 \%$ of target 
concentration by injecting in triplicates. The mean percent recovery was calculated using the following formula. ${ }^{26}$

$$
\begin{aligned}
\text { Recovery }(\%)= & (\text { Recovered concentration } / \text { Injected } \\
& \text { concentration }) \times 100
\end{aligned}
$$

\section{Precision}

The method precision (closeness of agreements measured by changing the different instances) was examined through intra-day and inter-day analysis of samples. ${ }^{27}$ For intra-day analysis, three replicates of the samples $(n=3)$ at each level of $80 \%, 100 \%$ and $120 \%$ of target concentration $(1 \mu \mathrm{g} / \mathrm{mL})$ were analysed on the same day. Whereas for inter-day analysis, samples were analysed on the second day by using the same chromatographic conditions and same sample concentrations that are freshly prepared. Peak area, $\%$ recovery and \% RSD were calculated to determine method precision.

\section{Robustness}

Robustness or ability of the entire methodology to remain unaltered by a small and intentional change in different parameters was checked after a change in mobile phase composition of ACN:0.1\% formic acid from 40:60 \% to 38:62 \% and 42:58 \% v/v, and flow rate of 1 to 0.9 and $1.1 \mathrm{~mL} / \mathrm{min}$. Further, the effect on the accuracy of the result after varying the method conditions was analyzed. At each variation, 80\%, 100\% and $120 \%$ of target concentration solution was injected in triplicates $(n=3)$. The robustness of the method was determined from the $\%$ RSD of peak area and mean $\%$ accuracy.

\section{Specificity}

Specificity of the technique was determined to examine capability of the developed analytical method in separating the analyte from a complex mixture. It was determined by evaluating excipients interference in duvelisib quantification. Duvelisib is available in capsule dosage form under the brand name COPIKTRA. This capsule contains duvelisib along with its excipients.

In the specificity study, a comparative analysis between blank, blank with excipients, blank with excipients spiked with drug and only drug chromatograms was conducted. The diluent (MeOH: water, 50:50, \%v/v) mixture was used as blank. The blank with excipients solution was prepared by dissolving $25 \mathrm{mg}$ of each of the above-mentioned excipients in $10 \mathrm{~mL}$ of diluent. The solution of drug spiked in a blank with excipients was prepared by adding $10 \mathrm{mg}$ of duvelisib and $25 \mathrm{mg}$ of each excipient in a volumetric flask and dissolving in $10 \mathrm{~mL}$ of diluent. These two solutions were sonicated for $10 \mathrm{~min}$ for complete solubilization and then centrifuged at $25^{\circ} \mathrm{C}$ at $10,000 \mathrm{rpm}$ for $10 \mathrm{~min}$. After centrifugation, supernatant was withdrawn and further diluted to have $1 \mu \mathrm{g} / \mathrm{mL}$ solution of duvelisib. A separate $1 \mu \mathrm{g} / \mathrm{mL}$ sample solution of duvelisib was prepared after suitable serial dilution from the stock solution. All four sample solutions (blank, blank with excipients, blank with excipients spiked with drug and only drug) were injected into the HPLC system at the same chromatographic conditions. The chromatograms were analysed and compared to verify any possible interference due to the excipients in drug quantification.

\section{RESULTS AND DISCUSSION}

\section{Optimization of chromatographic condition}

Composition of the mobile phases was varied to achieve an optimum chromatographic method. Different types of modifiers including formic acid, ammonium acetate and ammonium formate were employed for optimizing the chromatographic behavior of the analyte. However, elution of duvelisib with a good peak shape was obtained with $0.1 \%$ formic acid (FA) in water. ${ }^{28}$ We optimized the method with $0.1 \% \mathrm{FA}$ in water as it was easy to prepare without complex weighing and $\mathrm{pH}$ adjustment requirements. Amongst the various ACN:0.1\% FA in water ratios $(15: 85,30: 70$ and 40:60), 40:60 \% ratio showed a good peak shape of duvelisib. Isocratic elution at $1 \mathrm{~mL} / \mathrm{min}$ flow was shown to have optimum retention of duvelisib in the stationary phase used in this method. The detection wavelength selected for the estimation of duvelisib was $286 \mathrm{~nm}$. The optimum chromatographic condition with good peak separation was achieved using $\mathrm{C}_{18}$ column $(250 \times 4.6 \mathrm{~mm}, 5 \mu \mathrm{m})$ (Agilent Zorbax Eclipse Plus). The sample was injected at a volume of $10 \mu \mathrm{L}$ for each run. The RT for duvelisib was observed at $4.16 \mathrm{~min}$.

\section{Method validation}

\section{System suitability}

To determine the system suitability, various chromatographic attributes were taken into consideration before the analysis. There was no significant variation observed in any of the system suitability parameters of retention time, theoretical plate, asymmetry and tailing factor. 


\begin{tabular}{|c|c|}
\hline \multicolumn{2}{|c|}{ Table 1: Prediction of DL and QL. } \\
\hline Concentration $(\boldsymbol{\mu g} / \mathrm{mL})$ & Area \\
\hline 0.05 & 3142 \\
\hline 0.1 & 6038 \\
\hline 0.2 & 11047 \\
\hline 0.5 & 28492 \\
\hline 1.0 & 56074 \\
\hline 2.0 & 110575 \\
\hline 5.0 & 277349 \\
\hline Standard error & 394.57 \\
\hline Slope & 55211.84 \\
\hline Correlation coefficient & 0.999 \\
\hline Intercept & 389.15 \\
\hline Predicted $\mathrm{DL}(\mu \mathrm{g} / \mathrm{mL})$ & 0.02 \\
\hline Predicted $\mathrm{QL}(\mu \mathrm{g} / \mathrm{mL})$ & 0.07 \\
\hline
\end{tabular}

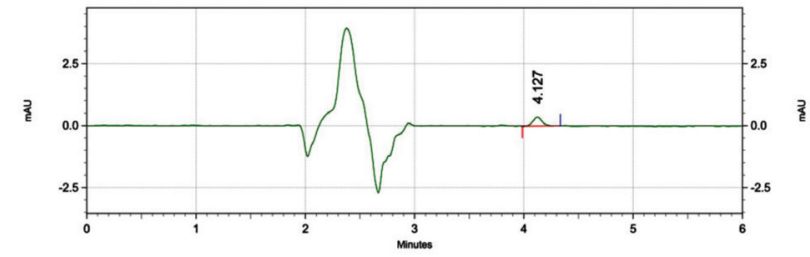

Figure 2: Representative chromatograms of duvelisib at low level

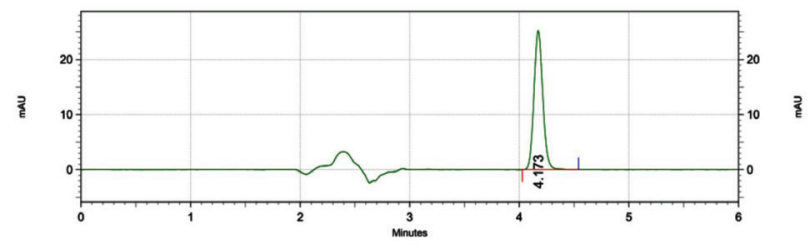

Figure 3: Representative chromatogram of duvelisib at its upper limit of quantification.

\section{Sensitivity}

Sensitivity was established through LOD and LOQ determination. The LOD and LOQ for duvelisib were predicted which was confirmed through their replicate injections and calculating the relative standard deviation (RSD) (Table 1). The LOD and LOQ values for the method were observed as $20 \mathrm{ng} / \mathrm{mL}$ and $70 \mathrm{ng} /$ $\mathrm{mL}$, respectively. A representative chromatogram at the LOQ level is shown in Figure 2.

\section{Linearity}

A seven point calibration curve was plotted for duvelisib to establish the linearity. The linearity was established within a range from 0.07 to $5 \mu \mathrm{g} / \mathrm{mL}$ which dictate that the method is linear. The regression coefficient $\left(r^{2}\right)$ for

\begin{tabular}{|c|c|c|c|c|}
\hline Level & 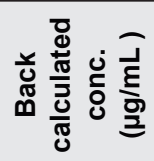 & œ & $\begin{array}{l}\widehat{o} \\
\text { ồ } \\
\text { ô }\end{array}$ & 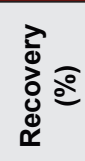 \\
\hline $80 \%(0.8 \mu \mathrm{g} / \mathrm{mL})$ & 0.76 & 1.94 & 1.99 & 95 \\
\hline $100 \%(1.0 \mu \mathrm{g} / \mathrm{mL})$ & 0.95 & 1.78 & 1.85 & 95.16 \\
\hline $120 \%(1.2 \mu \mathrm{g} / \mathrm{mL})$ & 1.16 & 1.88 & 1.24 & 97.38 \\
\hline
\end{tabular}

\begin{tabular}{|c|c|c|c|c|c|c|}
\hline 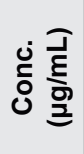 & 迎 & 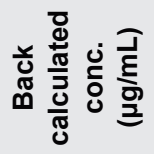 & 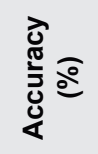 & के & 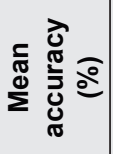 & 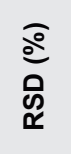 \\
\hline \multirow{3}{*}{0.80} & 51040 & 0.85 & 105.40 & \multirow{3}{*}{1.83} & \multirow{3}{*}{103.52} & \multirow{3}{*}{1.77} \\
\hline & 49268 & 0.82 & 101.75 & & & \\
\hline & 50078 & 0.83 & 103.42 & & & \\
\hline \multirow{3}{*}{1.00} & 59348 & 0.98 & 98.05 & \multirow{3}{*}{0.96} & \multirow{3}{*}{99.05} & \multirow{3}{*}{0.97} \\
\hline & 60506 & 1.00 & 99.96 & & & \\
\hline & 60010 & 0.99 & 99.14 & & & \\
\hline \multirow{3}{*}{1.20} & 70856 & 1.17 & 97.55 & \multirow{3}{*}{1.88} & \multirow{3}{*}{99.63} & \multirow{3}{*}{1.87} \\
\hline & 73521 & 1.22 & 101.22 & & & \\
\hline & 72727 & 1.20 & 100.13 & & & \\
\hline
\end{tabular}

duvelisib was 0.999 . A representative chromatogram at upper limit of quantification (ULOQ) level is shown in Figure 3.

\section{Accuracy}

Accuracy was evaluated by percentage recovery at three different concentrations of $80 \%, 100 \%$ and $120 \%$ of the target concentration. Percentage recovery of duvelisib in the developed method was obtained within 95.00 to $97.38 \%$. Results for accuracy of the method are shown in Table 2.

\section{Precision}

Intra-day and inter-day precision results were examined through RSD (\%) of the results. Intra-day precision was evaluated by analysing three different samples of different concentrations of $80 \%, 100 \%$ and $120 \%$ of target concentration on same day and experimental conditions. The RSD for duvelisib was found to be within 0.97 to $1.87 \%$ (Table 3). Inter-day precision was determined by injecting the samples of same three different levels on different days and RSD was found to be within 1.25 to $1.99 \%$ (Table 4). The experimental values ( $\%$ RSD) were found to be within the acceptable limit ensuring the desired precision of the developed method. ${ }^{22}$ 


\begin{tabular}{|c|c|c|c|c|c|c|}
\hline $\begin{array}{l}\text { Conc. } \\
(\mu g / m L)\end{array}$ & Area & $\begin{array}{c}\text { Back calculated } \\
\text { conc. } \\
(\mu \mathrm{g} / \mathrm{mL})\end{array}$ & Accuracy (\%) & SD & $\begin{array}{c}\text { Mean accuracy } \\
(\%)\end{array}$ & $\begin{array}{l}\text { RSD } \\
(\%)\end{array}$ \\
\hline \multirow{3}{*}{0.80} & 45330 & 0.77 & 95.78 & \multirow{3}{*}{1.94} & \multirow{3}{*}{97.63} & \multirow{3}{*}{1.99} \\
\hline & 46125 & 0.78 & 97.46 & & & \\
\hline & 47162 & 0.80 & 99.65 & & & \\
\hline \multirow{3}{*}{1.00} & 58081 & 0.98 & 98.18 & \multirow{3}{*}{1.79} & \multirow{3}{*}{96.57} & \multirow{3}{*}{1.85} \\
\hline & 55990 & 0.95 & 94.64 & & & \\
\hline & 57316 & 0.97 & 96.89 & & & \\
\hline \multirow{3}{*}{1.20} & 69954 & 1.19 & 98.54 & \multirow{3}{*}{1.23} & \multirow{3}{*}{98.5} & \multirow{3}{*}{1.25} \\
\hline & 70785 & 1.20 & 99.71 & & & \\
\hline & 69042 & 1.17 & 97.26 & & & \\
\hline
\end{tabular}

\begin{tabular}{|c|c|c|c|c|c|c|}
\hline \multirow[b]{2}{*}{ Level } & \multicolumn{3}{|c|}{ Mobile phase ratio $42: 58 \% \mathrm{v} / \mathrm{v}$} & \multicolumn{3}{|c|}{ Mobile phase ratio $38: 62 \% \mathrm{v} / \mathrm{v}$} \\
\hline & $\begin{array}{l}\text { Average conc. ( } \mu \mathrm{g} / \\
\mathrm{mL})\end{array}$ & $\begin{array}{l}\text { RSD } \\
(\%)\end{array}$ & $\begin{array}{c}\text { Accuracy } \\
(\%)\end{array}$ & $\begin{array}{l}\text { Average conc. } \\
\qquad(\mu \mathrm{g} / \mathrm{mL})\end{array}$ & $\begin{array}{r}\text { RSD } \\
(\%)\end{array}$ & $\begin{array}{c}\text { Accuracy } \\
(\%)\end{array}$ \\
\hline $\begin{array}{c}80 \% \\
(0.8 \mu \mathrm{g} / \mathrm{mL})\end{array}$ & $0.77+1.09$ & 1.14 & 95.89 & $0.78+0.79$ & 0.82 & 96.65 \\
\hline $\begin{array}{c}100 \% \\
(1.0 \mu \mathrm{g} / \mathrm{mL})\end{array}$ & $0.97+2.28$ & 2.37 & 96.15 & $0.97+2.10$ & 2.18 & 96.52 \\
\hline \multirow[t]{2}{*}{$\begin{array}{c}120 \% \\
(1.2 \mu \mathrm{g} / \mathrm{mL})\end{array}$} & $1.20+1.64$ & 1.65 & 99.06 & $1.19+0.80$ & 0.81 & 98.54 \\
\hline & \multicolumn{3}{|c|}{ Flow rate $0.9 \mathrm{~mL} / \mathrm{min}$} & \multicolumn{3}{|c|}{ Flow rate $1.1 \mathrm{~mL} / \mathrm{min}$} \\
\hline $\begin{array}{c}80 \% \\
(0.8 \mu \mathrm{g} / \mathrm{mL})\end{array}$ & $0.84+1.82$ & 1.74 & 104.53 & $0.85+3.41$ & 3.24 & 105.45 \\
\hline $\begin{array}{c}100 \% \\
(1.0 \mu \mathrm{g} / \mathrm{mL})\end{array}$ & $0.99+1.15$ & 1.16 & 98.72 & $0.99+0.85$ & 0.86 & 99.03 \\
\hline $\begin{array}{c}120 \% \\
(1.2 \mu \mathrm{g} / \mathrm{mL})\end{array}$ & $1.20+2.32$ & 2.34 & 99.49 & $1.20+1.20$ & 2.01 & 99.22 \\
\hline
\end{tabular}

\section{Robustness}

Minor changes such as alteration in mobile phase composition and flow rate were included in the experiment to check robustness of the developed method. The results indicate that there were no major changes in RT and peak area of the drug. Furthermore, RSD was found to be within 1.14 to $2.37 \%$ for mobile phase ratio 42:58 \% (ACN:0.1 \% FA in water) and 0.81 to $2.18 \%$ for mobile phase ratio $38: 62 \%$ (ACN:0.1 \% FA in water). Similarly, RSD was found to be within 1.16 to $2.34 \%$ for flow rate $0.9 \mathrm{~mL} / \mathrm{min}$ and 0.86 to $3.24 \%$ for flow rate 1.1 $\mathrm{mL} / \mathrm{min}$ (Table 5). Robustness study results revealed that the developed method was robust and analytical results remain unaffected due to minor changes in chromatographic conditions.

\section{Specificity}

Specificity was established by evaluating whether there was any interference of formulation excipients at the RT of the drug. Overlay of chromatograms of different samples containing excipients with blank and spiked drug is shown in Figure 4. The study revealed that there was an absence of any interfering peak of excipients at the RT of duvelisib as depicted in the Figure. The specificity was confirmed from the absence of any interference in the quantitative determination of duvelisib.

\section{CONCLUSION}

In this study, a simple, rapid, sensitive and cost-effective HPLC method for quantification of duvelisib has been established after required validation as per the ICH and 


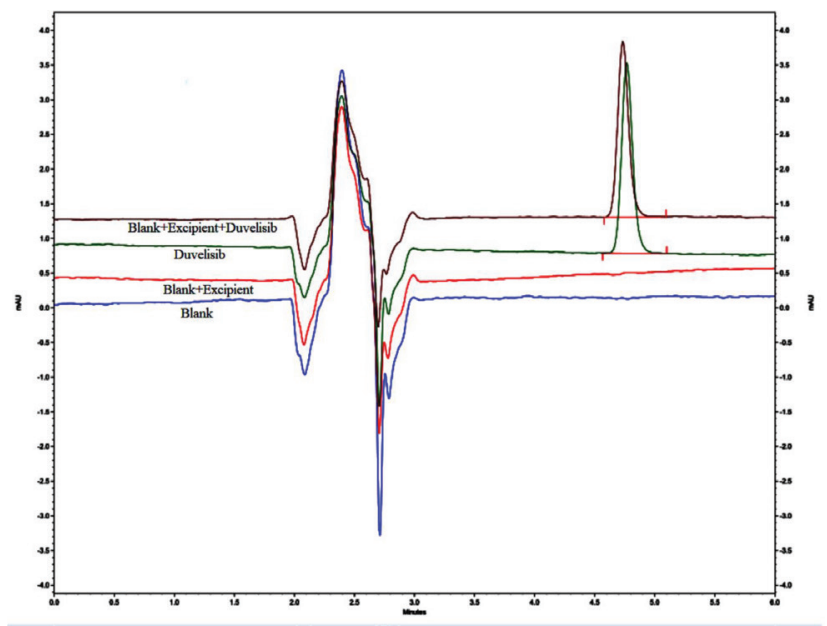

Figure 4: Overlay of chromatograms of different samples containing excipients with blank and spiked drug to signify the interference caused by the excipients (specificity study).

AOAC guideline. Parameters like specificity, linearity, accuracy, precision, specificity were evaluated during validation of the developed method. All validation results were within the acceptable limit as specified in the regulatory guidelines. The established quantitative analysis technique was confirmed to be sensitive, accurate, and precise in the validation experiment. The chromatographic run time was very short which is highly suitable for rapid analysis of routine quality control and stability samples of duvelisib. The method we have developed is about 90 times more sensitive than the previous method. Comparision of this method with existing methods is shown in Table 6. Specificity analysis confirmed that the method is selective for duvelisib in presence of commonly used excipients for its pharmaceutical formulation. This is the first time to report a quantitative assay method for duvelisib, which can quantify the analyte even at the nanogram level. The method will be suitable for sample analysis of quality control, stability, cross-contamination, dissolution study of sustained-release formulation and effluent analysis of duvelisib in pharmaceutical industries and research laboratories.

\section{ACKNOWLEDGEMENT}

We would like to thank the Department of Pharmaceuticals, Ministry of Chemicals and Fertilizers, Govt. of India, and National Institute of Pharmaceutical Education and Research-Ahmedabad for providing us the required support, infrastructure for this study.

\begin{tabular}{|c|c|c|c|c|}
\hline 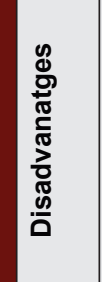 & 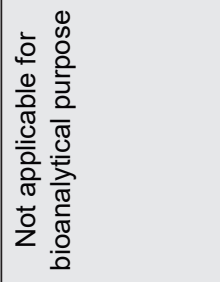 & 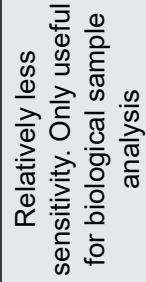 & 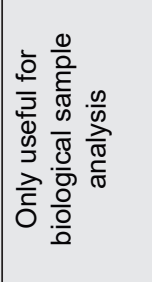 & 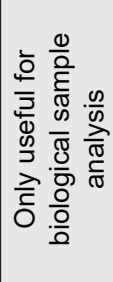 \\
\hline 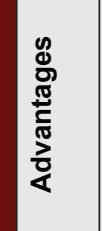 & 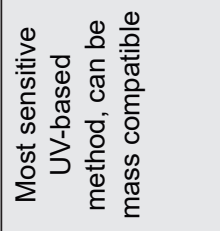 & 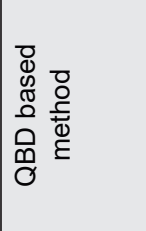 & 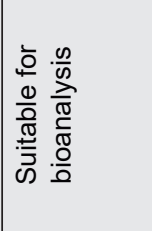 & 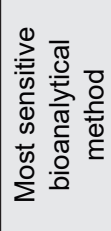 \\
\hline $\begin{array}{l}\frac{0}{20} \\
\frac{0}{0} \\
\frac{0}{0} \\
\frac{0}{\alpha} \\
\frac{1}{2}\end{array}$ & 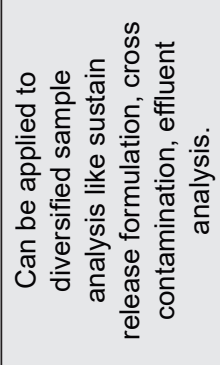 & 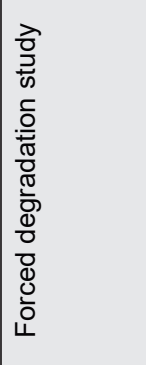 & 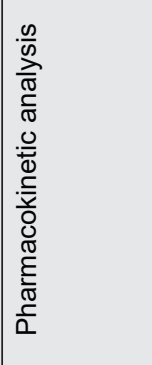 & 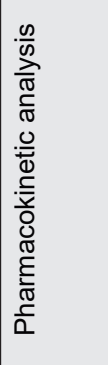 \\
\hline 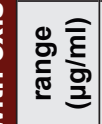 & $\begin{array}{l}0 \\
1 \\
0 \\
0 \\
0\end{array}$ & ஸ़่ & $\begin{array}{l}0 \\
1 \\
0 \\
0 \\
0\end{array}$ & 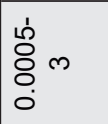 \\
\hline 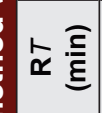 & $\frac{0}{\sigma}$ & $\begin{array}{l}L_{0} \\
\infty \\
\sim\end{array}$ & 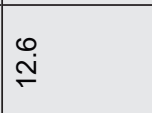 & 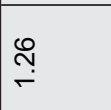 \\
\hline 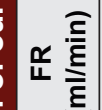 & - & 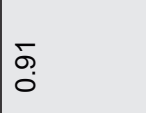 & - & $\stackrel{\nabla}{0}$ \\
\hline $\begin{array}{l}0 \\
0 \\
0 \\
\frac{0}{0} \\
0 \\
\frac{0}{0} \\
0 \\
0 \\
\Sigma\end{array}$ & 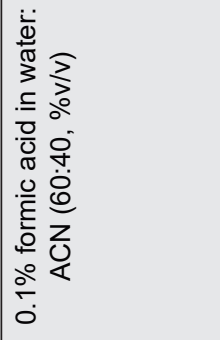 & 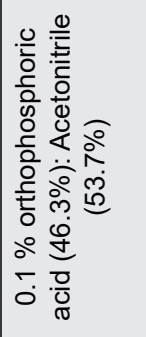 & 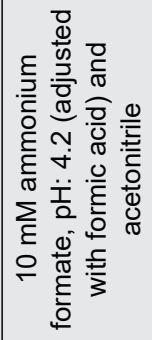 & 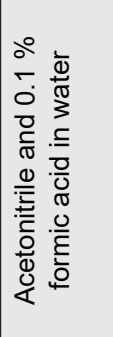 \\
\hline 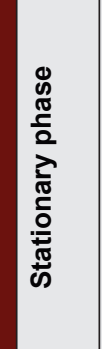 & 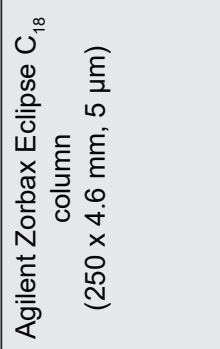 & 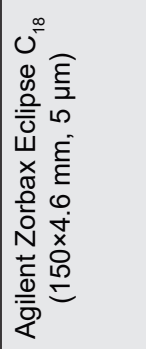 & 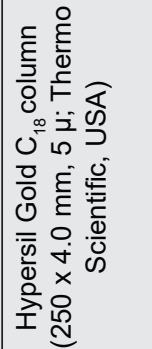 & 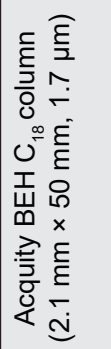 \\
\hline $\begin{array}{l}70 \\
0 \\
\frac{1}{0} \\
\Sigma \\
\Sigma\end{array}$ & 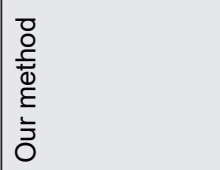 & 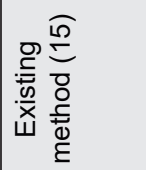 & 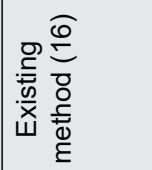 & 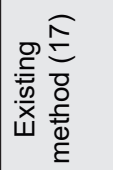 \\
\hline
\end{tabular}




\section{CONFLICT OF INTEREST}

The authors declare no conflict of interest.

\section{ABBREVIATIONS}

BCS: Biopharmaceutical classification system; PI3Ks: Phosphoinositide 3-kinases; USFDA: United States Food and Drug Administrartion; UPLC-MS/MS: Ultra performance liquid chromatography- tandem mass spectrometry; HPLC: High performance liquid chromatography; ICH: International Council for Harmonisation of Technical Requirements for Pharmaceuticals for Human Use; AOAC: Association of Official Analytical Collaboration; ACN: Acetonitrile; $\mathbf{M e O H}$ : Methanol; RP: Reversed phase; UV: Ultraviolet; LOD: Limit of detection; LOQ: Limit of quantitation; RSD: Relative standard deviation; ULOQ: Upper limit of quantification; FA: Formic acid; RT: Retention time.

\section{REFERENCES}

1. Center for drug evaluation and research. Multi-disciplinary review and evaluation Copiktra (duvelisib) [cited Jan 12, 2021]. Available from: https://www.accessdata.fda.gov/drugsatfda_docs/nda/2018/211155orig1 orig2s000multidiscipliner.pdf.

2. Center for drug evaluation and research [cited Jan 11, 2021]. Available from: https://www.accessdata.fda.gov/drugsatfda_docs/nda/2018/211155Orig1 Orig2s000ChemR.pdf.

3. Flinn IW, O'Brien S, Kahl B, Patel M, Oki Y, Foss FF, et al. Duvelisib, a novel oral dual inhibitor of PI3K- $\delta, \gamma$, is clinically active in advanced hematologic malignancies. Blood. 2018;131(8):877-87. doi: 10.1182/ blood-2017-05-786566, PMID 29191916.

4. O'Brien S, Patel M, Kahl BS, Horwitz SM, Foss FM, Porcu P, et al. Duvelisib, an oral dual $\mathrm{PI} 3 \mathrm{~K}-\delta$, $\gamma$ inhibitor, shows clinical and pharmacodynamic activity in chronic lymphocytic leukemia and small lymphocytic lymphoma in a Phase 1 study. Am J Hematol. 2018;93(11):1318-26. doi: 10.1002/ajh.25243, PMID 30094870.

5. Miller MS, Thompson PE, Gabelli SB. Structural determinants of isoform selectivity in PI3K inhibitors. Biomolecules. 2019;9(3):82. doi: 10.3390/ biom9030082, PMID 30813656.

6. Flinn IW, Patel M, Oki Y, Horwitz S, Foss FF, Allen K, Douglas M, Stern H, Sweeney J, Kharidia J, Kelly P, Kelly VM, Kahl B. Duvelisib, an oral dual $\mathrm{PI} 3 \mathrm{~K}-\delta, \mathrm{Y}$ inhibitor, shows clinical activity in indolent non-Hodgkin lymphoma in a phase 1 study. Am J Hematol. 2018;93(11):1311-7. doi: 10.1002/ ajh.25228, PMID 30033575.

7. Horwitz SM, Koch R, Porcu P, Oki Y, Moskowitz A, Perez M, Myskowski P, et al. Activity of the PI3K- $\delta, Y$ inhibitor duvelisib in a phase 1 trial and preclinical models of T-cell lymphoma. Blood. 2018;131(8):888-98. doi: 10.1182/blood-2017-08-802470, PMID 29233821.

8. Frustaci AM, Tedeschi A, Deodato M, Zamprogna G, Cairoli R, Montillo M. Duvelisib for the treatment of chronic lymphocytic leukemia. Expert Opin Pharmacother. 2020;21(11):1299-309. doi: 10.1080/14656566.2020.1751123, PMID 32292084.

9. Garces $A E$, Stocks MJ. Class 1 PI3K clinical candidates and recent inhibitor design strategies: a medicinal chemistry perspective. J Med
Chem. 2019;62(10):4815-50. doi: 10.1021/acs.jmedchem.8b01492, PMID 30582807.

10. Pokar D, Sahu AK, Sengupta P. Technology. LC-Q-TOF-MS driven identification of potential degradation impurities of venetoclax, mechanistic explanation on degradation pathway and establishment of a quantitative analytical assay method. J Anal Sci Technol. 2020;11(1):1-13.

11. Center for drug evaluation and research [cited Jan 11, 2021]. Available from: https://www.accessdata.fda.gov/drugsatfda_docs/nda/2018/211155orig1 orig2s000otherr.pdf.

12. Rodrigues DA, Sagrillo FS, Fraga CAM. Duvelisib:A2018 novel FDA-approved small molecule inhibiting phosphoinositide 3-kinases. Pharmaceuticals (Basel). 2019;12(2):69. doi: 10.3390/ph12020069, PMID 31064155.

13. Blair HA. Duvelisib: first global approval. Drugs. 2018;78(17):1847-53. doi: 10.1007/s40265-018-1013-4, PMID 30430368.

14. Full prescribing information [cited Jan 11, 2021]. Available from: https://www. accessdata.fda.gov/drugsatfda_docs/label/2018/211155s000lbl.pdf.

15. $\mathrm{CH}$ S, PA, KS N, Pawar KMA. Analytical quality by design approach in RP-HPLC method development and validation for the estimation of Duvelisib. Asian J Pharm Clin Res. 2021;14(2):99-108.

16. Siddesh A, Sriram D, Zakkula A, Kumar R, Dittakavi S, Zainuddin M, et al. Validated HPLC-UV method for simultaneous quantification of PI3K inhibitors, copanlisib, duvelisib and idelalisib in rat plasma: application to a pharmacokinetic study in rats. Biomed Chromatogr. 2020;35(4):e5015.

17. Shao Y, Xie S, Zhu H, Du X, Xu RA. Development of a novel and quick UPLC-MS/MS method for the pharmacokinetic analysis of duvelisib in beagle dogs. J Pharm Biomed Anal. 2020;187:113355. doi: 10.1016/j. jpba.2020.113355.

18. Gamal M. Analytical review: Analytical techniques for hyoscine N butyl bromide. Analyst. 2020;145(6):2025-37. doi: 10.1039/d0an00076k, PMID 32049090.

19. Hosny NM, Atia NN, El-Gizawy SM. A review on: analysis of certain drugs used in gout treatment. Microchem J. 2019;149. doi: 10.1016/j. microc.2019.05.055, PMID 103955.

20. Siddiqui MR, AlOthman ZA, Rahman N. Analytical techniques in pharmaceutical analysis: A review. Arab J Chem. 2017;10:S1409-21. doi: 10.1016/j.arabjc.2013.04.016.

21. $\mathrm{ICH}$. Q2 (R1) validation of analytical procedures. Int Counc Harmonisation Tech Requirements Regist Pharm Hum Use. 2005.

22. Guidelines for standard method performance requirements. Of Ficial Method Anal Appendix AOAC Int. 2016.

23. Porto DL, da Silva ARR, Oliveira AdS, Nogueira FHA, Pedrosa MdFF, Aragão CFS. Development and validation of a stability indicating HPLC-DAD method for the determination of the peptide stigmurin. Microchem J. 2020;157. doi: 10.1016/j.microc.2020.104921, PMID 104921.

24. Swamy N, Reddy VK, Thorat P, Sengupta PJB. JoPS. Development and validation of a stability indicating high-performance liquid chromatography method for trimethobenzamide. Braz J Pharm Sci. 2020;56.

25. Surve $\mathrm{DH}$, Jindal $\mathrm{AB}$. Development and validation of reverse-phase highperformance liquid chromatographic (RP-HPLC) method for quantification of efavirenz in efavirenz-enfuvirtide co-loaded polymer-lipid hybrid nanoparticles. J Pharm Biomed Anal. 2019;175:112765. doi: 10.1016/j.jpba.2019.07.013.

26. Mangla B, Beg S, Alam O, Ahsan W, Haque A, Patel KS, et al. Systematic development and validation of RP-HPLC method for simultaneous estimation of tamoxifen and sulphoraphane with specific application for nanolipidic formulations. Arab J Chem. 2020;13(11):7909-20.

27. Chaudhari VS, Borkar RM, Murty US, Banerjee S. Analytical method development and validation of reverse-phase high-performance liquid chromatography (RP-HPLC) method for simultaneous quantifications of quercetin and piperine in dual-drug loaded nanostructured lipid carriers. J Pharm Biomed Anal. 2020;186:113325. doi: 10.1016/j.jpba.2020.113325.

28. Núñez O, Lucci P. Applications and uses of formic acid in liquid chromatography-mass spectrometry analysis. Adv Chem Res. 2014;20:71-86. 
PICTORIAL ABSTRACT

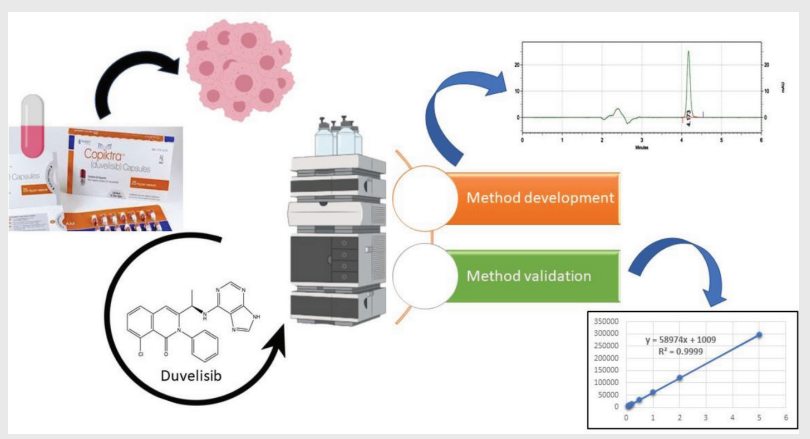

\section{SUMMARY}

A simple, rapid, and highly sensitive HPLC method for quantification of duvelisib has been developed and validated in this study. This is the first time to report a quantitative assay method for duvelisib, which can quantify the analyte even at the nanogram level. This method will be suitable for sample analysis of quality control, stability, cross-contamination, dissolution study of sustained-release formulation and effluent analysis of duvelisib in pharmaceutical industries and research laboratories.

\begin{abstract}
About Authors
Dr. Pinaki Sengupta is a faculty member of the Department of Pharmaceutical Analysis, National Institute of Pharmaceutical Education and Research (NIPER)- Ahmedabad, India. He is a Ph.D in Pharmacy from Jadavpur University, India. Dr. Pinaki has more than fourteen years of experience in academic and industry-based research. He has published more than seventy articles in various high impact international journals. He is serving as the Editorial Board Member of various scientific journals. His work has been cited more than 950 times in scientific articles.

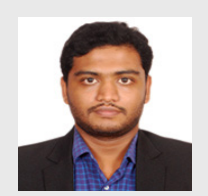

Amit Kumar Sahu is a Ph.D research scholar in the Department of Pharmaceutical Analysis, National Institute of Pharmaceutical Education and Research (NIPER) -Ahmedabad, India. He obtained his master degree in Pharmaceutical Analysis from National Institute of Pharmaceutical Education and Research (NIPER)- Hyderabad, India. His area of research includes forced degradation studies, metabolite profiling, and pharmacokinetic interaction studies. He has sound knowledge in the development and validation of stability indicating assay method, characterization of degradation products and bioanalytical method development and validation.

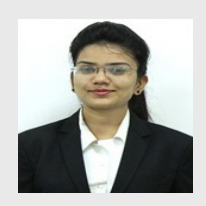

Dipali Sonawane is a Master of Science (Graduate) in Pharmaceutical Analysis from National Institute of Pharmaceutical Education and Research (NIPER) -Ahmedabad. Her primary research interest includes development and validation of analytical methods, stability studies and stress testing of pharmaceuticals. She has experience in the field of Analytical Research and Development in the pharmaceutical sector.

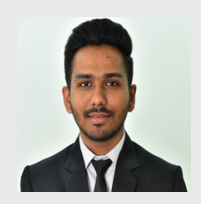

Tarang Jadav is a Ph.D. research scholar in the Department of Pharmaceutical Analysis, National Institute of Pharmaceutical Education and Research (NIPER)-Ahmedabad, India. He has done his master degree in Pharmaceutical Analysis from NIPER-Ahmedabad. His primary research interest includes transporter based drug-drug interaction studies, bioanalytical method development for the intracellular quantification of drugs, metabolite profiling and pharmacokinetic studies in different biological matrices.
\end{abstract}

Cite this article: Sonawane D, Sahu AK, Jadav T, Sengupta P. Establishment of a Rapid and Highly Sensitive Reverse-phase High-performance Liquid Chromatography Based Analytical Assay Method for Duvelisib. Indian $\mathrm{J}$ of Pharmaceutical Education and Research. 2022;56(1):287-95. 